NEWS, VIEWS AND COMMENTS

\title{
Human Dizygotic Twinning: Evolutionary-Based Explanations/Twin Research Reviews: Conjoined Twins in a Triplet Pregnancy; Double Embryo Transfer; Health Anxiety; Delayed Delivery of the Second Twin/In the Media: Digital Marketing Twins; Bereaved Twin at March for Our Lives; Exchange of Places; Football Players Reunite as Patriots
}

\author{
Nancy L. Segal \\ Department of Psychology, California State University, Fullerton, CA, USA
}

Human twinning poses a conundrum for researchers, given that the female uterus is optimally designed to carry a single fetus. Evolutionary explanations of dizygotic (DZ or fraternal) twinning provide insight and understanding of this reproductive event. This review is followed by summaries of recent twin research and reports concerning twins in a triplet pregnancy, double embryo transfer; a twin study of health anxiety, and delayed delivery of the second twin. Twin events reported in the media include a pair of digital marketing twins, a speech by a bereaved twin at the March for Our Lives in Washington, D.C., twins who exchanged places, and a same-team reunion of twin football players.

\section{Human Dizygotic Twinning: Evolutionary-Based Explanations}

The birth of twins in virtually all human populations poses an intriguing conundrum for researchers because the female uterus is optimally designed to carry a single fetus. Twin and other multiple birth pregnancies pose higher frequencies of serious physical and health hazards for both mothers (e.g., preeclampsia, delivery complications) and infants (e.g., immature lung development, growth retardation), relative to non-twin pregnancies (Segal, 2017). In the last several decades, evolutionary explanations of dizygotic (DZ or fraternal) twinning have provided new insights into this relatively rare event.
It is also the case that twinning varies across human groups, with the world's highest rate occurring in Benin at $27.9 / 1,000$, and the world's lowest rate occurring in Vietnam at 6.2/1,000 (Smits \& Monden, 2011). These figures combine monozygotic ( $\mathrm{MZ}$ or identical) and $\mathrm{DZ}$ twins, but because MZ twinning occurs fairly uniformly across human

ADDRESS FOR CORRESPONDENCE: Nancy L. Segal, Department of Psychology, California State University, Fullerton, CA 92834, USA.E-mail: nsegal@fullerton.edu 
groups, natural variation in the $\mathrm{DZ}$ twinning rate largely explains the population differences. The $\mathrm{DZ}$ twinning rate varies, but not exclusively, because of genetic differences related to reproductive characteristics in females. DZ twinning has also been variously linked to maternal age, maternal height, maternal weight, parity, and coital frequency among other factors (Segal, 2017).

It is common knowledge that older women (age 35 and beyond) are more likely to conceive DZ twins, due to increased chances of multiple ovulation (Segal, 2017). This event has been a presumed reproductive error, since the vast majority of females release just one egg at a time. However, some provocative explanations for the continued occurrence of human DZ twinning, especially among older mothers, have been offered by evolutionary-based investigators. One of the first such theories rests on the insurance ova hypothesis', which stipulates that while selection does not favor multiple births it does favor multiple conception attempts in each estrous cycle (Anderson, 1990). Releasing more than one ovum enhances the probability of producing a newborn, thus generating the following two predictions: (1) ovum production should exceed the rate of birth, which it appears to do, and (2) multiple ovulation offers insurance against genetic defects because the embryos have different genotypes.

Ball and Hill (1999) expanded upon Anderson's reasoning with their idea that $\mathrm{DZ}$ twinning can be considered to be a byproduct of selection for multiple ovulation that sometimes eventuates in an error, namely the birth of twins. As such, polyovulation reduces the risks of both embryo defects and conception failure. Their thinking led them to develop an 'insurance ova/pre-implantation selection model' and to test the hypothesis that embryo defect rates and DZ twinning rates should covary. According to the model, one prediction would be that a low genetic defect rate should indicate strong pre-implantation selection (and a low DZ twinning rate), whereas a high genetic defect rate should indicate weak pre-implantation selection (and a high DZ twinning rate).

Data on rates of twinning and Down syndrome, available for 25 populations, were used to assess their hypothesis regarding twinning and genetic defects. A strong correlation was observed between the twinning rate and Down syndrome births $(r=0.58, p<.01)$, even after controlling for maternal age $(r=0.65, p<.01)$. The only outlier in this analysis was Nigeria with an extremely high rate of DZ twinning, especially among the Yoruba in the western part of the nation. Note that, until recently, Nigeria held the world's record for the highest twinning rate, but that nation is currently second to Benin (Smits \& Monden, 2011).

As an aside, in the late 1990s when I was writing my first book, Entwined Lives, it occurred to me that DZ twinning might be understood at both proximal and functional levels. At the proximal level, multiple ovulation could be con- strued as a reproductive error, as indicated above. However, at the functional level, it might reflect a final effort by older women toward genetic representation in subsequent generations, as they near the end of their reproductive period. I excitedly emailed my late colleague Dr Linda Mealey with this idea, but she informed me that another investigator, Scott Forbes, had published this same conclusion in 1997, work he expanded upon in 2005 (Forbes, 1997; 2005). His work is reviewed next, labeled as the 'relaxed screening hypothesis' and the 'insurance strategy'.

The relaxed screening hypothesis offers an evolutionary approach to the rise in birth defects with maternal age. It asserts that older mothers should become less selective about their offspring quality in that (1) defective offspring are better than no offspring - approximately $50 \%$ of females with Down syndrome are fertile (National Down Syndrome Society, 2018) and having a normal child later in life may reduce the cost of a maladaptive one. (There have been three documented cases of children born to two Down syndrome fathers; see Pradhan, Dalal, Khan, \& Agrawal, 2006). Relaxing the maternal screen increases the chance of bearing a genetically defective child, but also a normal child. This can be seen as a kind of maternal trade-off. This argument is further supported by the observation that (2) the increased incidence of multiple births in older mothers supports the theory of relaxed maternal screening. This increase is clearly seen among mothers, as shown by the Ball and Hill (1999) analysis, while there is only a weak association between Down syndrome births and advanced paternal age.

In summary, Forbes (2005) suggests that 'Twinning is not about twins. It is about avoiding pregnancy failure'. He further asserts that 'twinning is also about avoiding twins. Mothers risk DZ twinning only when twin births are unlikely or when they are better prepared for the steep costs of twinning than most' (p. 114). He also describes a practical side to his work, namely that if restoration of the maternal screen were possible, then the defective births that are so difficult for families to face might be prevented.

These ideas about DZ twinning have been further examined by Helle (2008) in correspondence with the editor of the journal Human Reproduction, but recast as the 'terminal reproductive investment' hypothesis. This title captures the concepts outlined above with regard to the increased frequency of DZ twinning among older mothers and the relaxation of screening mechanisms. Some additional ideas advanced in this article are that survival to adulthood is a good proxy for maternal investment in children. Data are cited to show that: (1) twin births produce more offspring than non-twin births; (2) twins born to older mothers are not at higher risk of premature deliveries than younger mothers in fact, older mothers deliver heavier triplets than younger mothers; and (3) no adverse effects of being born a twin versus a singleton have been reported - one report found 
that both $\mathrm{MZ}$ and $\mathrm{DZ}$ twins outlive non-twin individuals (Sharrow \& Anderson, 2016), although this finding requires replication.

The presence of MZ and DZ twins, as well as MZ/DZ triplets, quadruplets and higher order multiples in human populations offer simple and elegant ways of examining factors affecting trait development. We often take these rare individuals for granted - but their origins and continued representation are fascinating questions that require additional creative answers.

\section{Twin Research Reviews}

\section{Conjoined Twins in a Triplet Pregnancy}

A rare case of symmetric thoracoomphalopagus conjoined twins was observed in a triplet pregnancy in Turkey (Ozcan et al., 2017). Thoracoomphalopagus twins, the most common type of conjoined twinning (DeRuiter, 2011), involve fetuses fused from the upper chest to the lower chest. The occurrence of a conjoined twin pair in a triplet pregnancy is estimated to occur in less than $1 / 1,000,000$ deliveries $(\mathrm{Oz}$ can et al., 2017).

The pregnancy in question was diagnosed in a 28 -yearold Caucasian woman, who had previously delivered two healthy children. Conjoined twinning was suspected at the 17 th week of gestation and confirmed by ultrasound scans showing a dichorionic-diamniotic twin triplet pregnancy; one amniotic sac contained a normal male fetus, while the other amniotic sac contained a set of male twins connected from the top of the upper thorax to the umbilicus. The conjoined twins had separate hearts, arms and legs, but a common liver. Magnetic resonance imaging also confirmed this diagnosis. The family initially chose to continue the pregnancy, then decided to selectively terminate one of the conjoined twins at week 21; however, the following day the demise of all three triplets was reported. It was noted that while selective fetal reduction lessens the mortality and morbidity of healthy co-twins, the abortion rate varies between $5 \%$ and $10 \%$, depending upon the gestational age.

\section{Double Embryo Transfer}

Outcomes of single embryo transfer (SET) versus double embryo transfer (DET) will be presented at the October 2018 meeting of the American Society for Reproductive Medicine, in Denver, Colorado (Morin et al., 2018). A sample of 2,725 women who failed to conceive following their first SET and had at least two remaining embryos was identified. The live birth rate for SET was $63.7 \%$; the 1,015 women who failed to conceive had either SET or DET. The live birth-rate difference between these two groups was not statistically significant ( $58.5 \%$ vs. $63.8 \%)$, but the multiple gestation rate per live birth was significantly higher in the DET group than in the SET group (49.8\% vs. $1.3 \%$ ). Interestingly, the same finding was reported by Robbert
Berkhout of the Netherlands at the 16th International Twin Congress, in Madrid, Spain, November, 2017 (Segal, 2018). Note: The number of women who failed to conceive with either SET or DET was incorrectly reported as 989 in the published abstract. The correct number is 1,015 as I suspected and confirmed with the first author (Morin, 2018).

\section{Twin Study of Health Anxiety}

Health anxiety (HA) is marked by worry or belief that one has contracted a life-threatening illness. An Australian twin study was conducted to assess the nature of the relationship between HA and anxiety and obsessive-compulsive symptoms (López-Solà et al., 2018). Participants were volunteer MZ twins enrolled in the Australian Twin Registry - 3,100 twins received a questionnaire by mail, with follow-up recruitment by telephone. The final sample was comprised of 202 male pairs and 294 female pairs, with a mean age of 34.4 years $(S D=7.72)$. The data were analyzed by ICE FALCON, a procedure testing for causality between symptoms of HA and symptoms of anxiety and obsessiveness. It was determined that (1) elevated levels of anxiety and/or obsessive-compulsive tendencies may make HA more likely, and that (2) fears related to HA may increase the chances of physical anxiety. The authors indicated that these findings require replication via longitudinal studies.

\section{Delayed Delivery of the Second Twin}

The optimal management of twin pregnancies in which membranes rupture early has not been fully determined. A case with both unfavorable maternal and fetal outcomes was reported by researchers in Portugal in an attempt to draw needed attention to this problem (Galvão et al., 2016). Diamniotic-dichorionic twins were conceived spontaneously by a 36-year-old female and diagnosed at week 17 . Pre-term rupture of membranes for the first twin occurred at 20 weeks, 4 days into her pregnancy. The mother complained of painful uterine contractions 9 days later, at which time she delivered a fetus, but not the placenta. A decision was made to delay delivery of the second twin; however, at 23 weeks, 4 days, following abdominal pain and vaginal hemorrhage, the second twin was delivered. The mother 
developed septic shock, required treatment with ventilation and norepinephrine, but eventually recovered. Unfortunately, neither twin survived given their extreme prematurity.

The authors noted that other management strategies and procedures might have been followed. Amniocentesis to assess infection in the second twin could have been per- formed, but would have precluded a delayed delivery. Cerclage (the sewing of the cervix to prevent early delivery; American Pregnancy Association, 2018) is sometimes done when one twin is delivered early, but the case in question did not suggest cervical incompetence. Hopefully, additional reporting of treatment and outcomes in such cases will facilitate finding the optimal management plan.

\section{In the Media}

\section{Digital Marketing Twins}

Fratzke Media is a digital marketing consulting firm run by identical twins, Ryan and James Fratzke. Their highly matched appearance makes it extremely likely that they are identical twins. I met them several years ago - the twins are 2014 graduates of my campus, California State University, Fullerton (CSUF). News of their success was recently reported in a local newspaper in southern California (Fawthrop, 2018).

The twins explain their abilities as grounded in the skills they acquired as CSUF students and as Disneyland and tech company employees. Their current mission is to develop strategies for solving clients' problems (customer needs or employee concerns) via website development, digital ads, and other means. The Fratzke brothers recognize a special chemistry between themselves that allows them to go from an idea to a plan to an actual product. It seems that their talents surfaced as children when they staged plays, but especially when they created promotional materials for these productions. Their future appears bright - they aim to positively affect the people who hire them and to motivate their own employees to launch businesses of their own.

Learning about these twins and their accomplishments is exciting. Future News, Views, and Comments column will summarize twin research on occupational choice and satisfaction, featuring different twins who work together as writers and comedians.

\section{Bereaved Twin at March for Our Lives}

On September 20, 2017, fraternal twin Zaire Kelly of Washington, D.C. was walking home from Thurgood Marshall Academy where he attended high school. The teenager was shot in the head by a 19-year-old who tried to rob him. His surviving twin brother, Zion, spoke on behalf of his brother and family, as well as countless other students who participated in the March for Our Lives in Washington, D.C., on March 24, 2018 (Foxfd.com Staff, 2018). This event was a response to the February 14, 2018 mass shooting at Marjory Stoneman Douglas High School, in Parkland, Florida that killed 17 students. The twins appear to be fraternal, based on a photograph shown on MSNBC, March 26, 2018.

The twins' family is proposing the Zaire Kelly School Zone Amendments Act. Its purpose would be to create safe zones for students traveling to and from school. It would also enlarge the meaning of student to provide further protection. I contacted the executive director of Thurgood Marshall Academy to arrange an interview with Zion; my request was forwarded to the family, but there has been no response. The loss of a twin has been largely overlooked by bereavement counselors and other health professionals, but is a devastating of loss for the surviving twin (Segal, 2017).

\section{Exchange of Places}

An identical twin and sex offender, Alexander Delgado, was serving prison time in his country of Peru (Cerulllo, 2018). During a visit with his twin brother Giancarlo, Alexander ushered him to his cell, drugged him, put on his clothing and escaped. He evaded capture for 13 months and when he was finally found he explained to authorities that he was 'desperate' to see his mother. His correct identification was made via fingerprint characteristics, which are not identical even in identical twins (Segal, 2017). When Giancarlo was interviewed on television he insisted that he loves his twin brother, but will need to speak to him regarding forgiveness.

\section{Football Players Reunite as Patriots}

The National Football League (NFL) players, Devin and Jason McCourty, were reunited as teammates after playing apart for 8 years (Hannable, 2018). In 2010, Devin was drafted by the Boston Patriots, while Jason played with the Tennessee Titans beginning in 2009 and, most recently, the Cleveland Browns before joining his twin brother in 2018 (Tennessee Titans, 2017; Warner-Gough, 2018). The twins, who appear to be identical based on inspection of photographs, played college football together at Rutgers University. Both twins are very excited at the prospect of being together again. 


\section{References}

America Pregnancy Association. (2018). Cervical cerclage. Retrieved from http://americanpregnancy.org/ pregnancy-complications/cervical-cerclage/.

Anderson, D. J. (1990). On the evolution of human brood size. Evolution, 44, 438-440.

Ball, H. L., \& Hill, C. M. (1999). Insurance ovulation, embryo mortality and twinning. Journal of Biosocial Science, 31, 245-255.

Cerulllo, M. (2018). Inmate drugged, swapped places with twin brother to see mom. New York Daily News. Retrieved from http://www.nydailynews.com/news/world/ inmate-drugged-swapped-places-twin-brother-momarticle-1.3823443.

DeRuiter, C. (2011). Conjoined twins. The Embryo Project Encyclopedia. Retrieved from https://embryo.asu.edu/pages/ conjoined-twins.

Fawthrop, W. (2018). Cal State Fullerton alums the Fratzke twins meld charm, Disney skills and digital smarts. Orange County Register. Retrieved from https: //www.ocregister.com/2018/03/21/cal-state-fullertonalums-the-fratzke-twins-meld-charm-disney-skillsand-digital-smarts/.

Forbes, L. S. (1997). The evolutionary biology of spontaneous abortion in humans. Trends in Ecology \& Evolution, 12, 446-450.

Forbes, S. (2005). A natural history of families. Princeton NJ: Princeton University Press.

Fox5dc.com Staff. (2018). Twin brother of Zaire Kelly, DC teen shot to death in robbery, speaks at March for Our Lives. Fox5. Retrieved from http://www.fox5dc. $\mathrm{com} /$ news/local-news/brother-of-dc-teen-gun-violencevictim-speaks-at-march-for-our-lives.

Galvão, G., Rocha, R., Buchner, C., \& Braga, J. (2016). Delayed interval delivery of a second twin resulting in septic shock in the mother. Nascer e Crescer [Birth and Growth Medical Journal], 25, 241-243.

Hannable, R. (2018). Could McCourty twins finally play together in New England? WEEI Sports Radio Network. Retrieved from http://www.weei.com/blogs/ryan-hannable/ could-mccourty-twins-finally-play-together-

new-england.
Helle, S. (2008). Why twin pregnancies are more successful at advanced than young maternal age? A potential role of 'terminal reproductive investment.' Human Reproduction, 23, 2387-2389.

López-Solà, C., Bui, M., Hopper, J. L., Fontenelle, L. F., Davey, C. G., Pantelis, C., ... Harrison, B. J. (2018). Predictors and consequences of health anxiety symptoms: A novel twin modeling study. Acta Psychiatrica Scandinavica, 137, 241251.

Morin, S. J. (Personal correspondence, 15 May, 2018).

Morin, S. J., Neal, S. A., Tiegs, A. W., \& Scott, R. T. (2018). Double embryo transfer or a euploid blastocyst after a failed single embryo transfer does not improve live birth rate but significantly increases the risk of twins. Fertility and Sterility, 109, e9.

National Down Syndrome Society (2018). Sexuality. https:// www.ndss.org/resources/sexuality/

Ozcan, H. C., Ugur, M. G., Mustafa, A., \& Kutlar, I. (2017). Conjoined twins in a triplet pregnancy: A rare obstetrical dilemma. Saudi Medical Journal, 38, 307-309.

Segal, N. L. (2017). Twin mythconceptions: False beliefs, fables, ands fact about twins. San Diego, CA: Elsevier.

Segal, N. L. (2018). The 16th International Twin Congress: Highlights from Madrid. Twin Research and Human Genetics, 21, 67-72.

Sharrow, D. J., \& Anderson, J. J. (2016). A twin protection effect? Explaining twin survival advantages with a twoprocess mortality model. PLoS One, 11, e0154774.

Smits, J., \& Monden, C. (2011). Twinning across the developing world. PLoS One, 6, e25239.

Pradhan, M., Dalal, A., Khan, F., \& Agrawal, S. (2006). Fertility in men with Down syndrome: a case report. Fertility and Sterility, 86(6), 1765-e1.

Tennessee Titans. (2017). Team. NFL Internet Network. Retrieved from http://www.titansonline.com/team/roster/ jason-mccourty/fcf9622c-3d3a-4b51-b97e617ba76dbd0c/.

Wagner-McGough, S. (2018). Browns Trade Jason McCourty to Patriots, Reuniting him with twin brother Devin. CBSS Sports. Retrieved from https://www.cbssports. $\mathrm{com} / \mathrm{nfl} /$ news/browns-trade-jason-mccourty-topatriots-reuniting-him-with-twin-brother-devin/. 